\title{
Pesticide Distribution in Pond Sediments from an Agricultural Catchment (Auradé, SW France)
}

\author{
Chaumet Betty 1,2,3,*, Probst Jean-Luc 1,2,3, Eon Pierre 1, Payré-Suc Virginie 1,2,3, Granouillac Franck \\ 1,2,3, Camboulive Thierry 1,2,3, Riboul David 1, Pautot Corinne 1, Tavella Marie-Josée 1, Trochon \\ Benjamin ${ }^{1}$ and Probst Anne 1,2,3,* \\ 1 Laboratory of Functional Ecology and Environment, University of Toulouse, CNRS, Toulouse, France \\ France \\ 2 LTSER Zone Atelier Pyrénées-Garonne, CNRS, University of Toulouse, France \\ 3 LTER Bassin versant Auradé, IR OZCAR, CNRS, University of Toulouse, France \\ * Correspondence: betty.chaumet@toulouse-inp.fr (C.B.); anne.probst@ensat.fr (P.A.)
}

\begin{abstract}
Currently, pesticides massively used in agricultural areas end up in watercourses, since they are usually final receptacles of organic contamination. A large number of ponds occurred in agricultural catchments, but their role regarding pesticides behaviour, is still poorly investigated. The Pestipond project aims to fill this gap, particularly considering the Bassioue pond, which is located in the carbonated agricultural upper sub-catchment of the Auradé critical zone observatory (Gers, France), with a wheat/sunflower crop rotation and a steep slope. Our current objective was to understand (i) how and where pesticides are stored in the sediments, and (ii) the relationship with the characteristics of sediments, supposed to be highly involved in the storage and degradation of pesticides. A regular quadrat of cores ( $\# 20 \mathrm{~cm}$ ) was sampled at autumn 2019 and summer 2020 . A set of pesticide molecules was quantified as well as sediment texture, and organic carbon and nitrogen content. The results highlighted that sediment texture varied between upstream and downstream of the pond, as did the spatial distribution of pesticides, which was partly controlled by their physicochemical properties. More hydrophilic pesticides had more affinity with the finest fractions of the sediments.
\end{abstract}

This study also highlights the difference in storage of these molecules according to depth. In particular, boscalid $(\operatorname{logKow}=3)$ was found in greater quantities in the deepest samples, in relation with increasing coarse silt content. Finally, a seasonal effect is also observed on pesticide levels. This work provides new knowledge on the role of ponds in pesticide storage, dissipation and transfer downstream.

Keywords: Pond; pesticides; bottom sediments; agricultural catchment; storage; spatial distribution

\section{Introduction}

Owing to their ubiquitous presence in soils and watercourses, pesticides represent a major issue in environmental risk assessment, particularly in agricultural areas. Indeed, for many years now, pesticides have been massively detected in agricultural catchment areas, notably in wetlands [1], [2]. These wetlands play an essential role in the transfer of contaminants and in the quality of aquatic systems [3]. Among these wetlands, natural or artificial ponds play a major role in pesticide dissipation. Indeed, they are composed of many compartments which can interact with these contaminants. For example, they contain a water column that can transport pesticides, as well as sediment and vegetation, which can store and possibly degrade these contaminants [4]. Thus, they represent a dynamic and complex environment, which have not yet been studied in depth [5].

Among the processes inherent in this system, storage mechanisms play a major role in the dissipation of pesticides, particularly in bottom sediments. Particularly in erosive areas, this compartment is constantly undergoing evolution relative to processes of sedimentation and 
resuspension. Thus, the upper layer of sediment which is in constant interaction with the water column is the most reactive. Due to their configuration, ponds can extend the retention time of water flows and, by extension, of contaminants [6], [7]. This is the case, for example, of pesticides sorbed onto suspended particles in the water column, which can drop and sediment during water retention. Indeed, the sedimentation of particles can be modulated by different parameters such as the texture of these particles (clays, silts, sands, gravels) [8], [9]. The larger the particles are (gravel or sand type), the higher their upstream sedimentation when they get into the water reservoir [10]. Conversely, smaller particles (such as clays or silts) generally settle further downstream of the water reservoirs.

Other physico-chemical parameters may influence pesticide storage in sediments, such as the carbon content [11] or the physico-chemical properties of these molecules [12]. According to their $\operatorname{logKow}$, they do not tend to be adsorbed onto the same type of particles [13]. More specifically, the sediments have a greater affinity with molecules with a logKow higher than 3 [14]. Also, a greater adsorption capacity of fine particles such as silts or clays was evidenced, due to their larger specific surface areas [15].

In this context, the ANR Pestipond project took place, with the aim to characterise the role of wetlands and especially natural or artificial ponds in the dissipation of pesticides in agricultural lands. In the present study, we investigated the spatial distribution of pesticides in the upper layers of the sediments of a small upstream pond and the relationship with their physico-chemical characteristics, to understand their behaviour.

\section{Material and Methods}

\subsection{Study site and field campaigns}

The studied pond is located in the upstream part of the carbonated Auradé catchment (Gers, SW France) which is a French eLTER site. It is mainly cultivated with a yearly rotation of sunflower and wheat, and undergoes a significant soil erosion because of steep slopes and significant storm events in spring [16], [17] (Figure 1). This water reservoir is $60 \mathrm{~m}$ long, 11 to $21 \mathrm{~m}$ wide with $0.5 \mathrm{~m}$ ofwater column and $3 \mathrm{~m}$ ofsediment layer depth. Following several erosive storm events, sediments accumulated in the pond leading to a reduced water level of 30 to $50 \mathrm{~cm}$ depth depending on the season. A major flood event in 2018, contributes to the formation of a sediment bed at the entrance of the pond, creating a small secondary upstream pond (named PM) of $7.5 \mathrm{~m}$ long and $5 \mathrm{~m}$ wide connected to the major one. On this sedimentary bed, a natural vegetation has taken place.

Two core sampling campaigns were carried out in autumn $\left(18^{\text {th }}\right.$ November 2019$)$ and summer ( $3^{\text {rd }}$ July 2020). Each time, eight cores of the upper sediment layer were collected using a UWITEC core drill (Ø: $8.8 \mathrm{~cm})$ according to a previously established regular quadrat (Figure 1). During both sampling campaigns, surface sediments were collected (the first $2 \mathrm{~cm}$ ). Deeper sediments from the cores were also collected in the second campaign: from 2 to $12 \mathrm{~cm}$ depth (called "Middle") and from 12 to $17 \mathrm{~cm}$ depth (called "Bottom").

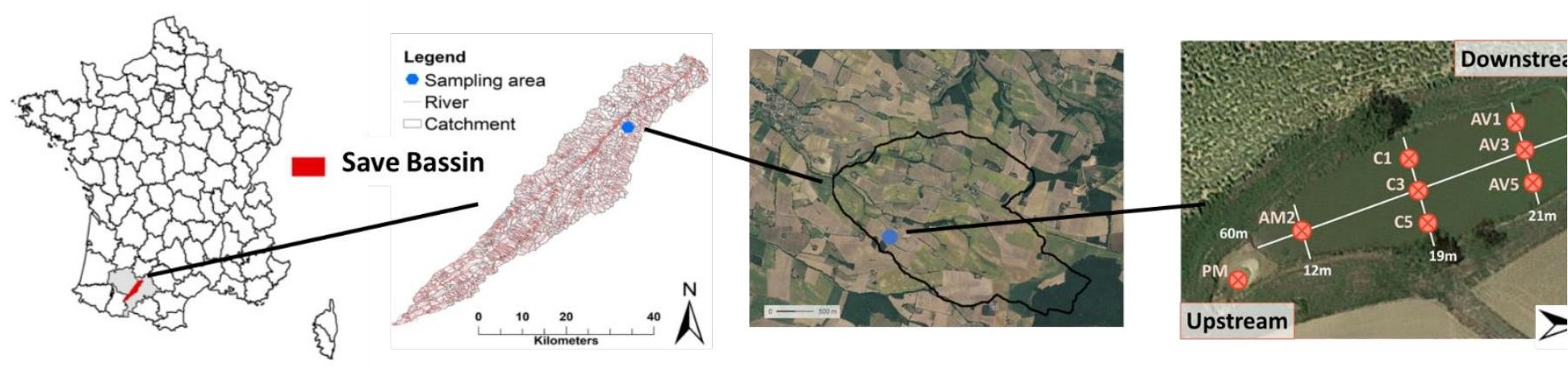

Figure 1. Location of the field study site at (from left to right): country scale, basin scale from $\mathrm{Wu} \mathrm{PhD}$ (in progress), sub-catchment scale (map from Google map) and pond scale (map from Google map) with sampling points. 


\subsection{Sample preparation and analysis}

Once in the laboratory, the samples were dried at room temperature and then disintegrated smoothly using an agate mortar and pestle, quartered and an aliquot was collected for microgranulometry analysis on the bulk sample. The rest of the samples was sieved in order to recover only the fine fraction $(<63 \mu \mathrm{m})$ for organic carbon, nitrogen and pesticide analysis. Microgranulometry was determined by laser diffraction (LA920-V2, Horiba) according to ISO 13320 guideline to determine the percentage of the sediment fractions: i.e. clays $(0-2 \mu \mathrm{m})$, fine $(2-20 \mu \mathrm{m})$ and coarse $(20-63 \mu \mathrm{m})$ silts, sands $(63 \mu \mathrm{m}-2 \mathrm{~mm})$ and gravels $(<2 \mathrm{~mm})$. Prior organic carbon and nitrogen analysis, performed by gas chromatography couple with a TCD detector (Flash2000 Thermo Scientific) following NF ISO 10694, NF ISO 13878 and NF EN 13137 guidelines, inorganic carbon was removed using hydrochloric acid, rinsed with ultrapure water and dried.

Relative to their contrasted chemical characteristics, three pesticides were quantified in surface and deep core sediment samples: metolachlor $(\operatorname{logKow}=2.9)$, boscalid $(\operatorname{logKow}=3)$ and tebuconazole $(\operatorname{logKow}=3.7)$. Pesticides were extracted from sediment matrix using firstly methanol and various steps of agitation ( $5 \mathrm{~min}$ vortex at $1200 \mathrm{rpm}, 30 \mathrm{~min}$ of ultrasound, and $5 \mathrm{~min}$ vortex at $1200 \mathrm{rpm}$ ). Then, samples were centrifugated $\left(6000 \mathrm{rpm}, 20 \mathrm{~min}\right.$ at $\left.4^{\circ} \mathrm{C}\right)$ in order to collect the supernatant for the second step of extraction. Contaminants were extracted from methanol matrix to SBSE bar (Stir Bar Sorptive Extraction) following a 3-h agitation. Finally, pesticides were thermo-desorbed and quantified using a GC-TD-MS/MS (TRACE 1300 - TSQ8000EVO, Thermo Fischer).

\section{Results and Discussion}

\subsection{Sediment characteristics}

For all the sediment samples (Surface, "Middle" and "Bottom"), the microgranulometry indicated that for most of the sediments, the fine silts $(2-20 \mu \mathrm{m})$ were predominant (Figure 2). With the exception of the "PM" sites for the "Middle" and "Bottom" sediment samples for the summer 2020 campaign, the percentage of fine silts varied from 58 to $82 \%$. Results were similar for the autumn campaign (data not shown). This percentage increased from upstream to downstream for the surface and bottom samples. On the other hand, a high percentage of coarser fraction was observable at the most upstream point of the pond ("PM") for the deeper samples of the second campaign. All of these results are consistent with the principle that larger and heavier particles settle more rapidly than smaller ones, and therefore in the upstream pond [18]. 


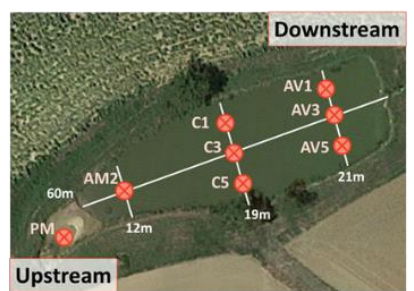

PM S

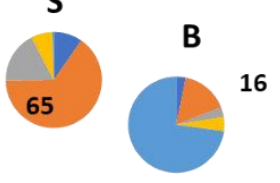

AM2

\section{$\mathrm{S}$}

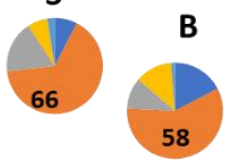

C1

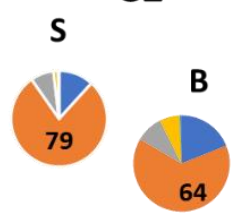

AV1

$\mathbf{S}$

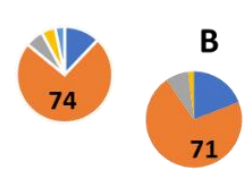

- Clays

- Coarses silts

- Gravels
- Fines silts

- Sands

\section{- Sands}

AV3

s

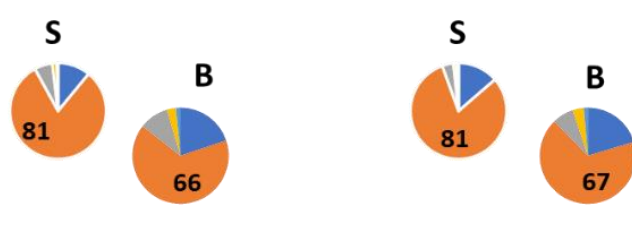

Figure 2. Distribution of the different size fractions in the sediments at the surface (" $\mathrm{S}$ ") and at the bottom ("B") of the different cores for the July 2020 campaign. The numbers indicated the percentages of the fine silt fraction.

\subsection{Pesticide storage in sediments}

Metolachlor concentrations averaged $2.6 \pm 0.3 \mu \mathrm{g} \cdot \mathrm{kg}^{-1}$, for the samples collected at the surface during the first campaign, and $1.3 \pm 0.1$ and $3.6 \pm 0.5 \mu \mathrm{g} \cdot \mathrm{kg}^{-1}$ at the surface and depth of the second campaign, respectively. The concentrations were respectively $5.5 \pm 0.4,3.3 \pm 0.1$ and $10.8 \pm 1.3 \mu \mathrm{g} . \mathrm{kg}$ ${ }^{1}$ for boscalid and $8.1 \pm 0.6,21.7 \pm 2.6$ and $8.3 \pm 1 \mu \mathrm{g} \cdot \mathrm{kg}^{-1}$ for tebuconazol, in the same order. These data illustrated that pesticides were not accumulated in the same way according to the season (due to different application periods) and between surface and depth, with molecule specificity. However, these values remain relatively low compared to what can be found in Mediterranean areas with high agricultural activity, with pesticide concentrations of several hundred g per kg [19].

\subsection{Influencing parameters}

\subsubsection{Role of sediment texture}

The results highlighted that the nature of the sediments influenced the distribution of pesticide storage. Firstly, a positive linear relationship was observed between the concentration of boscalid and metolachlor and the percentage of clay relative to the fine fraction (i.e. $<63 \mu \mathrm{m}$, Figure 3A) of the sediment, with higher slope for the former. Clay fractions acted thus as a significant controlling factor for these two pesticides, prevalently for boscalid. These results coincided with the data in the literature [8], [20], which also highlighted the important sorption capacity of clays. However, this was not observed for tebuconazole with clays (not shown), nor with the fine silt fraction, which is the dominant fraction (Figure 3B). Surprisingly, boscalid was also positively related to the coarse fraction of silt (Figure 3C), if we except the sites from the small upstream pond, which were very enriched in coarse fractions. 


\subsubsection{Seasonality effect}

A seasonal effect was noticeable, as observed for tebuconazol with concentrations two times higher in surface samples collected in summer compared with autumn (Figure 3B). The higher concentrations for samples collected in summer and on the surface of cores for tebuconazol could be explained by transport during spring flood event [21] since it was used generally in early spring as a fungicide on cereal crops (predominant in the upstream catchment). Then it might be degraded and/or diluted in autumn with increasing stream flow. However, at this stage, the results cannot explain what is the controlling factor for tebuconazol. The redox potential or the $\mathrm{pH}$ could influence the storage of this pesticide in the sediments [13], [22]. The lower concentrations of tebuconazol in the other samples could be also explained by its high rate of biodegradation by plants [23]. These observations were the reverse for boscalid and metolachlor (Figure 3A). One of the possible hypotheses to explain this observation would be the link to disctinct degradation phenomena (greater activity on the surface) or to a migration of these molecules deeper down. These two molecules have a logKow slightly lower than that of tebuconazol, which could explain their different behaviour. For boscalid, one of the possible explanations would also be its relatively rare use in summer.

\subsubsection{Depth storage process and other influencing parameters}

It was observed that pesticides were not accumulated in the same way according to depth. This was particularly the case for boscalid. For the same core, concentrations were on average three times higher in samples collected at the bottom of the core than at the surface (for the second campaign). The enrichment in clays and in coarse silts explained these higher boscalid concentrations with depth. Ii is the same pattern forclay enrichment and metolachlor content. As described by Farenhorst et al. [24], some pesticides do not have the same storage capacity depending on the depth considered. Indeed, the processes could be different depending on the depth and the inherent physico-chemical conditions (e.g. texture, redox potential, carbonates, oxides, $\mathrm{pH}$ ), and thus increase or decrease the sorption capacity of the pesticides [25].

Organic carbon did not have a marked influence on pesticide storage in those sediments since no correlation between particulate organic carbon content and pesticide concentrations could be demonstrated. Indeed, the organic carbon content did not exceed 1\% (data not shown), which was similar to the soil content [26]. Although studies have demonstrated the influence of organic carbon on pesticide sorption [11], [27], in this case, this parameter was not considered as a controlling factor.
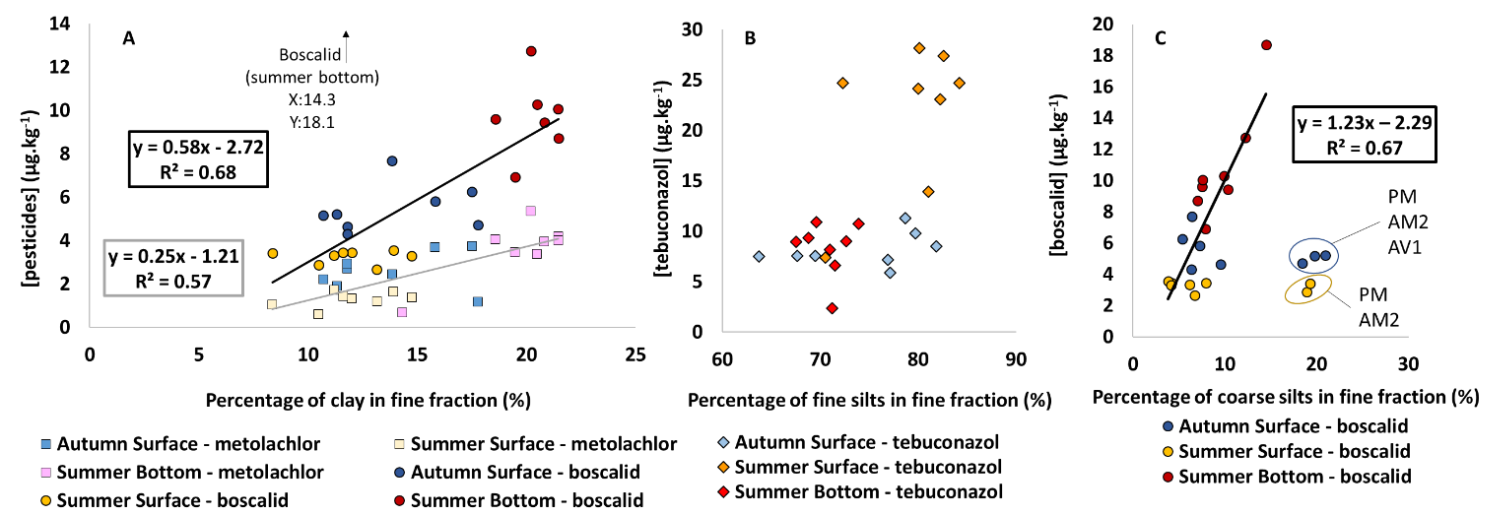

Figure 3. Relationships between the pesticide concentration (in $\mu \mathrm{g} \cdot \mathrm{kg}^{-1}$ ) and the percentage of the different fractions (clays, fine silts and coarse silts): A) boscalid and metolachlor vs clays, B) tebuconazol vs fine silts, C) boscalid vs coarse silts. The lines represent the linear regressions of the set of points for boscalid (in black, excepted outliers A: one sample out of graph and C: samples in the ellipses) and metolachlor (in grey).

\section{Conclusions}


This study allowed to characterise the spatial storage of pesticides in relation with the distribution of sediment texture, in a pond from an agricultural area. Although fine silts represent the main fraction, the results show that they are not responsible for pesticide accumulation in the sediments, while clays controlled metolachlor and boscalid contents, the latter being also surprisingly controlled by the coarse fraction. The influence of the seasonality in relation with the period of pesticide application was also highlighted. Finally, in addition to the influence of the texture, different processes might explain the pesticide enrichment with depth. This study provides new knowledge on the behaviour of pesticides and opens up many perspectives.

Author Contributions: B.C. and A.P. conceived and designed the experiments; B.C., A.P., V.P.-S., F.G., Thierry Camboulive, J.-L.P., M.-J.T. and B.T. performed the experiments; P.E., T.C. and B.C. prepared the samples; D.R. and C.P. performed the analysis; B.C., A.P., J.-L.P. and P.E. analyzed the data; B.C. and A.P. wrote the paper; J.L.P. reviewed and approved the paper; A.P. and J.-L.P. supervised the paper; A.P. and J.-L.P. managed the project administration and funding acquisition.

Acknowledgments: This work was possible thanks to the ANR within the framework of the PESTIPOND Project, which allowed financial support for analysis, field investigations and $\mathrm{BC}$ postdoc fellowhip. The authors acknowledge the physicochemical analysis platform (PAPC and PANCHO) of the University of Toulouse - Paul Sabatier for the analysis of microgranulometry, organic carbon and nitrogen content, and pesticides.

Conflicts of Interest: The authors declare no conflict of interest.

\section{Abbreviations}

The following abbreviations are used in this manuscript:

ANR: National Research Agency

eLTER: European Long-Term Ecosystem Research infrastructures

Pestipond: "Role of ponds in the transfer and impact of pesticides in surface waters of the critical

zone in agricultural environment". Project funded by the ANR which aims to characterise the role of ponds in pesticide dissipation

rpm: rotation per minute

SW: South-West

\section{References}

1. D. El Azzi, J. L. Probst, R. Teisserenc, G. Merlina, D. Baqué, F. Julien, V. Payre-Suc, and M. Guiresse, “Trace Element and Pesticide Dynamics During a Flood Event in the Save Agricultural Watershed: Soil-River Transfer Pathways and Controlling Factors," Water. Air. Soil Pollut., vol. 227, no. 12, 2016.

2. M. Rabiet, C. Margoum, V. Gouy, N. Carluer, and M. Coquery, "Assessing pesticide concentrations and fluxes in the stream of a small vineyard catchment - Effect of sampling frequency," Environ. Pollut., vol. 158, no. 3, pp. 737-748, 2010.

3. R. Schulz, "Field Studies on Exposure, Effects, and Risk Mitigation of Aquatic Nonpoint-Source Insecticide Pollution: A Review," J. Environ. Qual., vol. 33, no. 2, pp. 419-448, 2004.

4. G. Imfeld, M. Braeckevelt, P. Kuschk, and H. H. Richnow, "Monitoring and assessing processes of organic chemicals removal in constructed wetlands," Chemosphere, vol. 74, no. 3, pp. 349-362, 2009.

5. J. Vymazal, “Constructed wetlands for wastewater treatment," Ecol. Eng., vol. 25, no. 5, pp. 475-477, 2005.

6. C. Gregoire, S. Payraudeau, and N. Domange, "Use and fate of 17 pesticides applied on a vineyard catchment," Int. J. Environ. Anal. Chem., vol. 90, no. 3-6, pp. 406-420, 2010.

7. S. Stehle, D. Elsaesser, C. Gregoire, G. Imfeld, E. Niehaus, E. Passeport, S. Payraudeau, R. B. Schäfer, J. Tournebize, and R. Schulz, "Pesticide Risk Mitigation by Vegetated Treatment Systems: A Meta-Analysis," J. Environ. Qual., vol. 40, no. 4, pp. 1068-1080, 2011.

8. J. B. Weber, G. G. Wilkerson, and C. F. Reinhardt, "Calculating pesticide sorption coefficients ( Kd ) using selected soil properties," Chemosphere, vol. 55, no. 2, pp. 157-166, 2004.

9. D. El Azzi, F. Laurent, V. Roussiez, L. Chou, M. Guiresse, and J.-L. Probst, “Adsorption of Aclonifen, Alachlor, $\mathrm{Cd}$ and $\mathrm{Cu}$ onto Natural River Suspended Matter in the Context of Multi-Pollutions: Influence of Contaminant Co-Presence and Order of Input into the Aqueous Solution," Water, vol. 10, no. 9, p. 1222, 2018. 
10. Q. Wu, G. Riise, H. Lundekvam, J. Mulder, and L. E. Haugen, "Influences of suspended particles on the runoff of pesticides from an agricultural field at Askim, SE-Norway," Environ. Geochem. Health, vol. 26, no. 2, pp. 295-302, 2004.

11. L. Taghavi, J. L. Probst, G. Merlina, A. L. Marchand, G. Durbe, and A. Probst, "Flood event impact on pesticide transfer in a small agricultural catchment (Montoussé at Auradé, south west France)," Int. J. Environ. Anal. Chem., vol. 90, no. 3-6, pp. 390-405, 2010.

12. Y. Si, M. Wang, C. Tian, J. Zhou, and D. Zhou, “Effect of charcoal amendment on adsorption, leaching and degradation of isoproturon in soils," J. Contam. Hydrol., vol. 123, no. 1-2, pp. 75-81, 2011.

13. T. Katagi, “Behavior of Pesticides in Water - Sediment Systems," Rev Env. Contam Toxicol, vol. 187, pp. 133251, 2006.

14. L. Poissant, C. Beauvais, P. Lafrance, and C. Deblois, "Pesticides in fluvial wetlands catchments under intensive agricultural activities," Sci. Total Environ., vol. 404, no. 1, pp. 182-195, 2008.

15. R. E. Green, Pesticide-Clay-Water Interactions, W. D. Guen. Soil Science Society of America, 1974.

16. A. S. Perrin, A. Probst, and J. L. Probst, "Impact of nitrogenous fertilizers on carbonate dissolution in small agricultural catchments: Implications for weathering CO2 uptake at regional and global scales," Geochim. Cosmochim. Acta, vol. 72, no. 13, pp. 3105-3123, 2008.

17. V. Ponnou-Delaffon, A. Probst, V. Payre, F. Granouillac, S. Ferrant, A-S. Perrin, and J-L. Probst., "Long and short-term trends of stream hydrochemistry and high frequency surveys as indicators of the influence of climate change, agricultural practices and internal processes (Aurade agricultural catchment, SW France)," Ecol. Indic., vol. 110, no. November, 2020.

18. R. Budd, A. O'Geen, K. S. Goh, S. Bondarenko, and J. Gan, "Efficacy of constructed wetlands in pesticide removal from tailwaters in the central valley, California," Environ. Sci. Technol., vol. 43, no. 8, pp. 29252930, 2009.

19. I. Karaouzas, D. A. Lambropoulou, N. T. Skoulikidis, and T. A. Albanis, “Levels, sources and spatiotemporal variation of nutrients and micropollutants in small streams of a Mediterranean River basin," J. Environ. Monit., vol. 13, no. 11, pp. 3064-3074, 2011.

20. E. Maillard and G. Imfeld, "Pesticide mass budget in a stormwater wetland," Environ. Sci. Technol., vol. 48, no. 15, pp. 8603-8611, 2014.

21. R. Budd, A. O'geen, K. S. Goh, S. Bondarenko, and J. Gan, "Removal mechanisms and fate of insecticides in constructed wetlands," Chemosphere, vol. 83, no. 11, pp. 1581-1587, 2011.

22. B. C. Braskerud and K. Haarstad, "Screening the retention of thirteen pesticides in a small constructed wetland," Water Sci. Technol., vol. 48, no. 5, pp. 267-274, 2003.

23. T. Lyu, L. Zhang, X. Xu, C. A. Arias, H. Brix, and P. N. Carvalho, "Removal of the pesticide tebuconazole in constructed wetlands: Design comparison, influencing factors and modelling," Environ. Pollut., vol. 233, pp. 71-80, 2018.

24. A. Farenhorst, D.A.R. McQueen, I. Saiyed, C. Hilderbrand, S.Li, D.A. Lobb, P. Messing, T.E. Schumacher, S.K. Papiernik, and M.J. Lindstrom, "Variations in soil properties and herbicide sorption coefficients with depth in relation to PRZM (pesticide root zone model) calculations," Geoderma, vol. 150, no. 3-4, pp. 267277, 2009.

25. T. Bur, J. L. Probst, M. N'guessan, and A. Probst, “Distribution and origin of lead in stream sediments from small agricultural catchments draining Miocene molassic deposits (SW France)," Appl. Geochemistry, vol. 24, no. 7, pp. 1324-1338, 2009.

26. T. Bur, A. Probst, A. Bianco, L. Gandois, and Y. Crouau, "Determining cadmium critical concentrations in natural soils by assessing Collembola mortality, reproduction and growth," Ecotoxicol. Environ. Saf., vol. 73, no. 3, pp. 415-422, 2010.

27. L. Boithias, S. Sauvage, G. Merlina, S. Jean, J. L. Probst, and J. M. Sánchez Pérez, “New insight into pesticide partition coefficient $\mathrm{Kd}$ for modelling pesticide fluvial transport: Application to an agricultural catchment in south-western France," Chemosphere, vol. 99, pp. 134-142, 2014.

(C) 2020 by the authors. Submitted for possible open access publication under the terms and conditions of the Creative Commons Attribution (CC BY) license (http://creativecommons.org/licenses/by/4.0/). 